\title{
Factors Determining Quality Of Life of Geriatric Patients With HIV/AIDS: A Cross Sectional Study In South India
}

\author{
${ }^{1,}$ Sudhir MBBS.MD , ${ }^{2,}$ Deepa.K, MBBS, MD , ${ }^{3,}$ Ashok N.C MBBS MD , \\ ${ }^{4}$ Murali Dhar M Phil,PhD

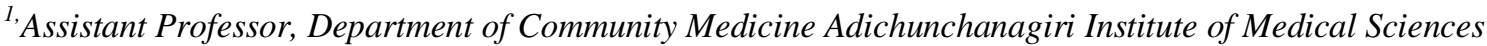 \\ B.G Nagara \\ ${ }^{2,}$ Assistant Professor, Department of Biochemistry Mysore Medical College and Research Institute \\ Mysore \\ 3. Professor and Head, Department of Community Medicine. J.S.S Medical College Mysore \\ ${ }^{4}$ Associate Professor,Department of Statistics, Manipal University Level 6, Health Sciences Library Building, \\ Manipal, India
}

\begin{abstract}
BACKGROUND: With the effectiveness of highly active antiretroviral therapy (HAART), people with HIV are aging.This number is expected to grow because of the aging of younger cohorts with HIV as well as new infections among persons over 60. With this upward shift in the age of people living with HIV, it is important to consider ways to promote successful aging in this growing population.
\end{abstract}

OBJECTIVE: To study the factors determining the quality of life of geriatric HIV/AIDS patients.

METHODOLOGY: This cross sectional study was done in 320 HIV/AIDS patients aged more than 60 years at ART centre K.R Hospital, Mysore. WHO-QOL-Bref a summarized quality of life questionnaire was used to assess the Quality of life and pre-structured and predesigned questionnaire was used for determining various factors influencing QoL. Statistical analysis was done using SYSTAT 13 software. To test the significance, $t$ test was applied.

RESULTS: Out of 325 patients included in the study 220 were male and 100 were female, 180 of them were from rural area and 210 were married. Multiple linear regression showed social relation had maximum effect on QoL. Factors which were statistically significantly related with better QoL were male sex, married marital status, higher education, employed, higher CD4 count and lower stage of disease.

CONCLUSION: The long-term effects of disease management on the aging population are something that both health care providers and policy makers often overlook. This is especially true with older persons with HIV/AIDS. Important epidemiologic and clinical differences exist between younger and older HIV-infected persons. Health care providers need to address the issues of sexuality in older patients and the similarity between the conditions associated with HIV and those of aging, such as dementia.

\section{KEY WORDS: CD4 Count, Quality of life ,HIV/AIDS, Geriatric}

\section{INTRODUCTION}

Thanks largely to the effectiveness of highly active antiretroviral therapy (HAART), people with HIV are aging $^{1,2}$.This number is expected to grow because of the aging of younger cohorts with HIV as well as new infections among persons over 60. With this upward shift in the age of people living with HIV, it is important to consider ways to promote successful aging in this growing population. As the general population ages and the generation of baby boomers moves into mid life, the percentage of older adults at risk for HIV will increase. In addition, there are currently HIV positive adults who have transitioned into older adulthood with the virus, as well as an increased number of aging partners, family members, and caregivers. Furthermore, with increased treatment options, the very nature of HIV/AIDS is projected to change, transforming a lethal, acute disease into a chronic illness that will inevitably affect increasing numbers of older people. The number of older adults vulnerable to HIV/AIDS infection suggest that older adults may not be aware of or protecting themselves from the risk factors associated with HIV/AIDS ${ }^{3}$. Often, older adults are not provided the information necessary to help protect themselves against infection. 
This is due in part to the general perception that the older adult population is not at risk for HIV, and society's reluctance to discuss behaviors that increase risk for transmission of HIV ${ }^{4}$. Social workers in many different fields of practice must be aware of the risk factors and transmission issues that leave older adults vulnerable to HIV/AIDS infection. The misconception that older people are not sexually active has, in large part, been a contributor in making older adults an invisible population to many AIDS educators and social workers. The total number of people living with HIV/AIDS (PLHA) in India is estimated at 24 lakh (19.3 - 30.4) in 2009. Children ( $<15 \mathrm{yrs})$ account for $3.5 \%$ of all infections, while $83 \%$ are the in age group 15-49 years and $13.5 \%$ are aged more than $50 \mathrm{yrs}$. With the universal availability of the ART drugs the life span of the patients have increased and more and more patients are entering in to older age group. As the life span has increased their quality of life has become an important focus for researchers and healthcare providers and what are the factors on which the QoL depends. Hence this study is done to know the factors determining the quality of life of geriatric HIV/AIDS patients of Mysore district and recommend suggestions to improve these factors

\section{MATERIALS AND METHODS:}

This study was a cross-sectional descriptive study which was done between January 2012 to August 2012, in HIV/AIDS patients aged more than 60 years with no severe psychiatric or cognitive problems coming to ART centre, K.R Hospital, Mysore. Ethical committee clearance was taken from institution time bound research committee and informed consent from the patients.

For estimating Quality of life instrument used was a summarized quality of life questionnaire of World Health Organization (WHO-QOL-Bref) that included 26 questions; 24 questions covered the four main domains such as physical health, psychological health, social functions, and environmental domain. Two questions included the satisfaction of overall health.

The items under the domains were:

Physical health: dependence of treatment, energy and fatigue, mobility, presence of pain and discomfort, sleep and rest, activities of daily living and perceived working capacity.

Psychological well being: affect, positive self concept, negative feelings, higher cognitive functions, body image and spirituality.

Social relations: social contacts, family support, sexual activity.

Environment: freedom, quality of home environment, physical safety and security, involvement in recreational activity, quality of health and social care and accessibility to services. Each answer to the question was measured in likert scale of 1-5, later each domain score was calculated which had a set of questions and the domain score was converted to a scale of 0-20, with minimum possible score of domain was given score 0 and maximum possible score of domain was given score 20 , and by multiplying this score with 5, final score in the range of 0-100 was calculated for each domain, and the mean of all the domain score together gave the quality of life score in the range of 0-100. And for each patient interviewed CD4 count was done at ART centre, K.R Hospital. The CD4 count cut off was taken as 350 because ART is started to HIV patients with CD4 count less than 350 according to NACO guidelines.

Statistical Analysis: The data entry and all the statistical analysis was performed by using Microsoft Excel and Epi-info software respectively. To test the significance between QOL and CD4 count t test was applied. The standard error of difference between means was employed to find out significant difference between domain scores and clinical categories. The difference between two sample mean is considered significant if the $\mathrm{p}$ value calculated is less than 0.05 .

Results: Total of 320 patients were interviewed, mean age of the patients was 65.06 years, and most of them were male.In the study it was seen that patients with CD4 count less than 350 were more than those patients with CD4 count more than 350, in both the group men were more than the females.(Table:2) When mean score of each domain was calculated it was seen that environmental domain contributed more to QoL score.(Table:3) As shown in the table 4, when regression coefficient was calculated for each domains against QoL it was seen that physical health had more effect on QoL. When combined regression coefficient was calculated it was found that social relation had more effect on QoL. In table 5 it can be seen that male sex, married patients, higher education, employed, patients from rural area, better CD4 count and better stage of disease had better QoL than other patients. 
Table 1: Characteristics of study population:

\begin{tabular}{|c|l|}
\hline Total No. of patients & 320 \\
\hline Mean age & 65.06 \\
\hline Sex: & \\
Male & 220 \\
Female & 100 \\
\hline Residence & \\
Urban & 180 \\
Rural & 140 \\
\hline Marital status: & \\
Unmarried & 20 \\
Married & 210 \\
Divorced & 20 \\
Widowed & 40 \\
Separated & 30 \\
\hline Education: & 120 \\
Illiterate & 30 \\
Primary school & 50 \\
Secondary school & 120 \\
Tertiary & \\
\hline & \\
\hline
\end{tabular}

Table 2: Comparison of male and female based on CD4 count:

\begin{tabular}{|c|c|c|c|}
\hline Clinical category CD4 count $\left(/ \mathrm{mm}^{2}\right)$ & Men & Women & Total \\
\hline$<350$ & 120 & 60 & 180 \\
\hline$\geq 350$ & 100 & 40 & 140 \\
\hline Total & 220 & 100 & 320 \\
\hline
\end{tabular}

Table 3: Mean domain score of QOL.

\begin{tabular}{|c|c|c|}
\hline S.No & WHO QoL Domains & Mean+S.D \\
\hline 1 & Physical domain & $58.4 \pm \underline{6} .02$ \\
\hline 2 & Psychological domain & $45.9 \pm 11.49$ \\
\hline 3 & Social domain & $42.5 \pm 17.31$ \\
\hline 4 & Environmental domain & $60.0 \pm 11.42$ \\
\hline
\end{tabular}

Table 4: Results summary of univariate and multiple linear regression analysis of QoL and the domains:

\begin{tabular}{|c|c|c|c|}
\hline S.No & Domains & $\begin{array}{c}\text { Regression } \\
\text { coefficient }\end{array}$ & $\mathbf{R}^{\mathbf{2}}$ \\
\hline 1 & Physical health & 0.703 & $21 \%$ \\
\hline 2 & Psychological well being & 0.636 & $63 \%$ \\
\hline 3 & Social relation & 0.439 & $69 \%$ \\
\hline 4 & Environment & 0.605 & $57 \%$ \\
\hline 5 & Physical health & 0.253 & $96 \%$ \\
& Psychological well being & 0.169 & \\
& Social relation & 0.316 & \\
& Environment & 0.233 & \\
\hline
\end{tabular}


Table 5: Factors determining QoL

\begin{tabular}{|c|c|c|c|c|}
\hline S.No & Factors & No. & Mean+S.D & p value \\
\hline 1 & $\begin{array}{c}\text { Sex } \\
\text { Male } \\
\text { Female }\end{array}$ & $\begin{array}{l}220 \\
100\end{array}$ & $\begin{array}{l}53.9 \pm 9.94 \\
48.2 \pm 5.87\end{array}$ & $<0.05$ \\
\hline 2 & $\begin{array}{c}\text { Marital Status } \\
\text { Married } \\
\text { Others }\end{array}$ & $\begin{array}{l}210 \\
110\end{array}$ & $\begin{array}{l}54.4 \pm 9.57 \\
47.8+6.82\end{array}$ & $<0.05$ \\
\hline 3 & $\begin{array}{c}\text { Education } \\
\text { Illiterate } \\
\text { Primary school } \\
\text { Secondary school } \\
\text { Tertiary }\end{array}$ & $\begin{array}{c}120 \\
30 \\
50 \\
120\end{array}$ & $\begin{array}{c}48.3 \pm 8.29 \\
52.5 \pm 9.42 \\
54.3 \pm 10.01 \\
55.3 \pm 9.45\end{array}$ & $<0.05$ \\
\hline 4 & $\begin{array}{c}\text { Employment } \\
\text { Yes } \\
\text { No } \\
\end{array}$ & $\begin{array}{c}230 \\
90 \\
\end{array}$ & $\begin{array}{l}54.0 \pm 9.34 \\
47.3 \pm 7.04 \\
\end{array}$ & $<0.05$ \\
\hline 5 & $\begin{array}{c}\text { Residence } \\
\text { Urban } \\
\text { Rural } \\
\end{array}$ & $\begin{array}{l}180 \\
140\end{array}$ & $\begin{array}{l}50.0 \pm 8.68 \\
54.8 \pm 9.40\end{array}$ & $<0.05$ \\
\hline 6 & $\begin{array}{c}\text { CD4 count } \\
<350 \\
\geq 350 \\
\end{array}$ & $\begin{array}{l}180 \\
140\end{array}$ & $\begin{array}{l}49.4 \pm 9.86 \\
55.6+7.07\end{array}$ & $<0.05$ \\
\hline 7 & $\begin{array}{c}\text { Stage of disease } \\
\text { I } \\
\text { II } \\
\text { III } \\
\text { IV } \\
\end{array}$ & $\begin{array}{c}90 \\
170 \\
40 \\
20\end{array}$ & $\begin{array}{l}61.4 \pm 6.01 \\
51.8 \pm 5.31 \\
39.1 \pm 5.35 \\
38.3 \pm 4.23\end{array}$ & $<0.05$ \\
\hline
\end{tabular}

\section{DISCUSSION:}

In previous studies it is seen that stigma appeared to diminish with age, with adults 60 and older reporting significantly lower stigma scores than those aged 50-59 years ${ }^{5}$. For older adults, the fear of stigma was related to concerns about rejection and to socially problematic consequences of HIV-related symptoms, which often resulted in social isolation as people limited social contacts ${ }^{6}$. Older adults with HIV often reported high rates of depression. Heckman et al found that $25 \%$ of older adults had moderate/severe depression which was associated with decreased physical well-being and social support ${ }^{7}$. In one of the few studies of social support for older adults, Schrimshaw et al found that it helped mitigate HIV distress, positively affecting both mood and distress levels ${ }^{8}$. Those with more co-morbidities and physical strain reported greater levels of social support ${ }^{9}$. After the introduction of ART, excess morbidity and mortality among older adults declined. Piette et al found older adults with HIV had lower self-rated health and poorer physical and social function compared to younger adults ${ }^{10}$. Nokes et al concluded that although older adults had higher mortality and co-morbidity rates, and more limited physical functioning than younger adults, there were no significant differences in quality of life ${ }^{11}$. Regardless of HIV status, the sexuality of older men is challenged by age. They recommend older men with HIV or at risk for HIV be screened for these conditions Siegel et al identified a number of factors, including side effects, stigma, and fatigue, that influenced levels of adherence ${ }^{12}$. Wutoh et al. (2001) found older adults generally more adherent than younger individuals, except when health problems intervened ${ }^{13}$. Barclay et al found poor adherence was twice as high for younger than older adults. Poor self-esteem and lack of perceived utility predicted younger adults' non-adherence, but only decreased levels of neuro-cognitive functioning predicted older adults' poor adherence ${ }^{14}$. In our study the environment domain had the maximum mean QoL score out of the four domains. This suggest that patients had better quality of home environment, physical safety and security, involvement in recreational activity, quality of health and social care, freedom and accessibility to services. The domain hardly hit was the social domain with score way behind the other three domains indicating that patients social contacts, family support and sexual activity were affected to a great extent. The regression coefficient of the domains has shown that social factors had maximum effect on the overall QoL scores suggesting that factors relating to social activity, social support and sexual relations were affected more than any other factors. When individual factors were compared it was found that males had better QoL score than females this suggest that female patients have to face lots of challenges in the society, they are neglected at each stage of their life, and those patients who have lost their husband find it very difficult to find 
their livelihood. Married patients had better QoL score than other patients this can be due to the fact that married patients have family members to care for them and they are socially more secured. Better education was associated with better QoL score,this may be due to better understanding of the disease, strict adhearance to treatment with frequent visit to the hospital and following correctly doctors advise. Patients who were working had better QoL score, this may be due to the fact that being employed keeps them busy, make them financially independent and make them feel that they are worthy. We have found that patients from rural area had better QoL than urban patients this finding may be due to the fact that patients from rural area have better access to fresh fruits and vegetables, they also have pollution free environment to live and are physically hard worker. It was also seen in the study that patients with better CD4 count had better QoL score than other patients, this can be explained by the fact that CD4 count is a pseudo marker of disease progression, as the disease progresses the viral multiplication increases and the CD4 count starts falling. In the study it was seen that patients with lower stage of disease had better QoL than patients with higher stage of disease, this can be explained on the fact that as the disease progresses the CD4 count falls and the patients become prone to opportunistic infections which in turn results in fall in QoL score.

\section{CONCLUSION:}

The long-term effects of disease management on the aging population are something that both health care providers and policy makers often overlook. This is especially true with older persons with HIV/AIDS. Important epidemiologic and clinical differences exist between younger and older HIV-infected persons. Health care providers need to address the issues of sexuality in our older patients and the similarity between the conditions associated with HIV and those of aging, such as dementia ${ }^{15}$.

To address this and other emerging issues, further research is needed on the long-term effects of antiretroviral therapy, and the many metabolic and hormonal changes that occur in HIV-infected persons. These studies need to identify cohorts of older persons because clinicians must delineate the lines between HIV and aging. Lifelong trends in sexual and social behaviors should also be examined so that at-risk behaviors, social trends, and public policy can be appropriately addressed. For some clinicians, a discussion of HIV with an older patient can feel foreign. An emerging challenge for health care providers is to find ways to better meet the needs of an aging HIV-infected population.

\section{REFERENCES:}

[1] Mack K, Ory M. AIDS and older Americans at the end of the Twentieth Century. JAIDS. 2003;33(2):S68-S75.

[2] Vance DE. Aging with HIV: Bringing the latest research to bear in providing care. Am J Nurs. 2010;110(3):42-47.

[3] National Association of HIV Over Fifty. (2003).Educational Tip Sheet HIV/AIDS and Older Adults.[Online]. http://www.hivoverfifty.org/tip.html

[4] Linsk, N. (1994). HIV and the elderly. Families in Society, 75 (6), 362-372.

[5] Emlet CA. Experiences of stigma in older adults living with HIV/AIDS: A mixed method analysis. AIDS Patient Care and STDs. 2007; 21(10):740-752.

[6] Siegel K, Schrimshaw EW, Brown-Bradley CJ, Lekas HM. Sources of emotional distress associated with diarrhea among late middle-age and older HIV-infected adults. Journal of Pain Symptom Management. 2010; 40(3):353-369.

[7] Heckman TG, Kochman A, Sikkema KJ. Depressive symptoms in older adults living with HIV disease: Application of the chronic illness quality of life model. Journal of Mental Health and Aging. 2002; 8:267-279.

[8] Schrimshaw EW, Siegel K. Perceived barriers to social support from family and friends among older adults with HIV/AIDS. Journal of Health Psychology. 2003; 8:738-752.

[9] Shippy RA, Karpiak SE. Perceptions of support among older adults with HIV. Research on Aging. 2005; 27:290-306

[10] Piette J, Watchel TA, Mor V, Mayer K. The impact of age on the quality of life in persons with HIV infection. Journal of Aging and Health. 1995; 7:163-178.

[11] Nokes KM, Holzemer WI, Corless IB, Bakken S, Brown MA, Powell-Cope GM, Turner J. Healthrelated quality of life in persons younger and older than 50 who are living with HIV/AIDS. Research on Aging. 2000; 22:290-310.

[12] Siegel K, Schrimshaw EW, Raveis VH. Accounts of non-adherence to antiviral combination therapies among older HIV-infected adults. Psychology Health \& Medicine. 2000; 5:29-42.

[13] Wutoh AK, Brown CM, Kumoji EK, Shah Daftary M, Jones T, Alie Barnes N, Powell NJ.

[14] Antiretroviral adherence and use of alternative therapies among older HIV-infected adults. Journal of the National Medical Association. 2001; 93:243-250.

[15] Barclay TR, Hinkin CH, Castellon SA, Mason KI, Reinhard MJ, Marion SD, Durvasula RS. Ageassociated predictors of medication adherence in HIV-positive adults: Health beliefs, self-efficacy, and neurocognitive status. Health Psychology. 2007; 26(1):40-49

[16] Alisky JM. The coming program of HIV-associated Alzheimer's disease. Med Hypotheses. 2007; 69(5):1140-1143. 